\title{
SEGREGATION AND SCHOOL ATTAINMENT
}

\author{
David Herbert \\ University of Wales Swansea, Singleton Park, Swansea SA2 8PP \\ United Kingdom \\ e-mail: d.t.herbert@swansea.ac.uk
}

\begin{abstract}
The article treats segregation as a form of urban life. Special emphasis is placed on the possibilities for education as one of the basic factors of the socio-economic structure of inhabitants and socio-economic differences in the social structure of the town.
\end{abstract}

Key words: Swansea, segregation, education

Residential segregation is an abiding feature of urban life. It has been the subject of a high volume of research in urban geography (Schnell and Ostendorf, 2002) and both the processes that underpin segregation and the patterns it produces are well understood. Much of traditional social geography of the city was founded on the depiction of these patterns of residential segregation and their outcomes as social areas, neighbourhoods and local communities (Davies and Herbert, 1993). The patterns are often found most clearly in studies of race and ethnicity and segregation and discrimination have become closely identified with those dimensions of urban life (Herbert, 1999). From an awareness of this fact, the range of quantitative techniques designed at demonstrating the extent of segregation has received greatest application in relation to measures of race and ethnicity. There are other bases for residential segregation (Pacione, 2001), such as migration history, age and household type, but among these social class or socio-economic status is the most general dimension that has continued significance. Measures of social status may be related to other variables such as ethnicity and age, but they do represent the most basic divisions within society and encompass qualities such as wealth or poverty, advantage or disadvantage, and privilege or deprivation. This underlying divisor of social class will vary in intensity from one type of society to another but remains a pervasive force. Within cities there are de facto separate residential areas as the products of social class segregation. The ability of the suburb to maintain and enhance its separateness and distinctive character is as much a testimony to the power of these processes as is the persistence of the impoverished slum. In the social geography of the city, this mosaic of residential areas with its visible symbols of power and prestige on the one hand and disadvantage and poverty on the other offers evidence of segregation and discrimination as key social, economic and political processes. 
Establishing the facts of segregation forms one part of urban geography. The next step is often that of investigating the impact of segregated residential areas on attitudes and behaviour in the city. Here the focus is upon attitudes and behaviour in relation to educational attainment and, in particular, the links between social background and school performance. There are several key questions:

- How significant is social class as an influence upon educational attainment?

- Are the facts of segregated residential areas mirrored by socially segregated schools and related levels of educational attainment?

- Are there social processes at work in the city, prompted in particular by the application of market place principles to the education sector, that serve to accentuate the differences and disparities?

\section{SOCIAL BACKGROUND AND ATTAINMENT}

There is a major body of evidence to support the contention that social background of the children affects the levels of their performance at school. The meanings of this social background effect are normally stated in terms of varying levels of parental support, conditions for study at home, and resources made available for learning. At key points in time, such as landmark examinations, children from higher social class homes are far more likely to receive extra tuition and guidance as preparation for the tests. Past evidence for this relationship exists in a variety of forms. There are major longitudinal studies, such as that by Douglas, Ross and Simpson (1968) that show clear evidence for a social background effect. In their study, the authors divided their cohort of children into social class groups matched by ability bands and showed that within any given ability band, the children from higher social class backgrounds performed better on a range of attainment tests. At age 16, for example, $94 \%$ of the upper middle class group children achieved a 'good' school certificate, compared with $69 \%$ of lower manual class children in the same ability band. $20 \%$ of children from the upper middle class group who fell into the lowest ability band still achieved good certificates compared to none from the lower manual class group. There are also literary sources of evidence and anecdotal comments that support the main hypothesis:

- OFSTED, the government school inspection agency in the United Kingdom spoke of the underlying social conditions outside the school gates that set limits on the success rates that individual pupils could achieve.

- A head teacher in Los Angeles argued that inner city children know very little compared to those who come from affluent areas.

There is also graphical evidence, such as that provided by Bowen (1997) in his city maps for American cities. These show close territorial correspondence between areas of poverty and areas of low educational attainment and vice versa.

Social background is a major factor influencing school attainment but there are certainly other factors to be considered (Figure 1). The ability of the individual child, as measured by tests of aptitude or intelligence, is clearly one factor. Much recent research has 
also focused on what might be termed the school effect (Reynolds and Cuttance, 1992). Are there good schools that enhance the attainment of children and bad schools that have an opposite effect? Clearly the school is a major player. There are questions however, which are not fully resolved:

- How do you measure and designate a good school?

- Is one of the criteria one of school performance on an attainment measure or should the quality of 'value-added' be given prominence?

- What other criteria are key elements in a good school?

- Is the school an aggregate that has little meaning unless it is broken down into its components of classes and individual teachers?

Figure 1: Influences on educational attainment

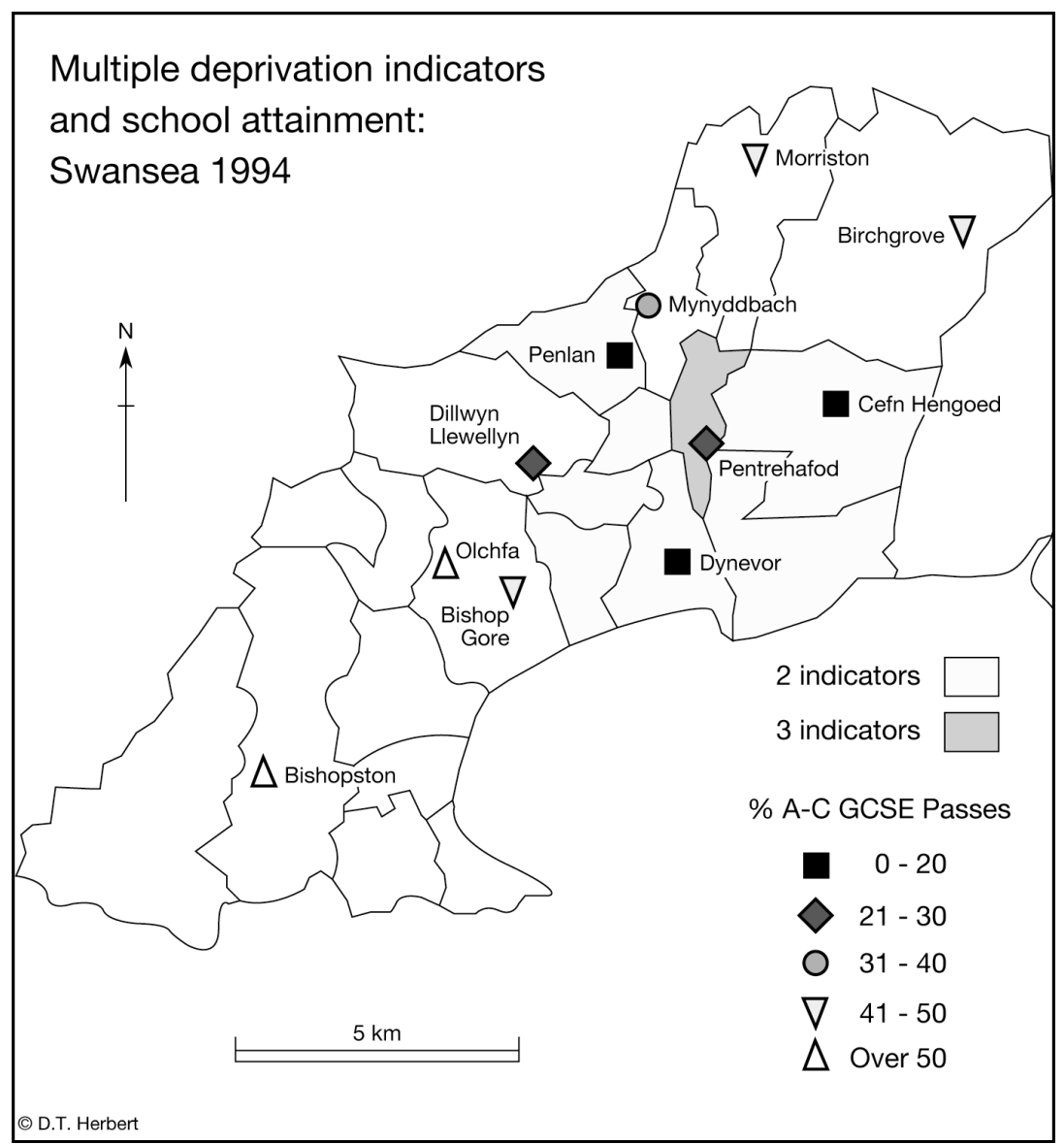

This is a major area of research that this study does not pursue (see, however, Reynolds, Creemers and Peters (eds.) 1989). The focus in this present paper is upon the influence of social background and the ways in which it works in a United Kingdom environment. 
The impact of social background upon attainment can be measured at a variety of scales from the populations of aggregate areas to individual pupils. Aggregate measures have the disadvantage of generalising individual differences within areas or schools but are widely used as reliable surrogates for individual analyses, provided proper care is taken in analysis and description of outcomes. This analysis has been conducted at an aggregate level using both school catchment areas and the individual schools. There is some use of qualitative data derived from interviews with head teachers. The means of measurement are:

- Social background measures for school catchments were based on census variables from the 1991 United Kingdom Census.

- The school measures of social background included some derived from data provided by the local education authority on numbers of pupils receiving free school meals and numbers classed as experiencing learning difficulties or being 'statemented'.

- Attainment was measured by performance in the national examinations set at age sixteen years. For some years during the 1980s and 1990s, league tables of school performance were published that allowed the success rates of pupils by schools to be known. The league tables were widely published and became very influential on parental perceptions of schools and upon school choice. The key measure of attainment used in the league tables and also in this study was the percentage of pupils entered for each school who achieved grade $\mathrm{C}$ or better in 5 or more subjects in the General Certificate of Education GCSE).

The case study is mostly based on the Swansea region with a total population of about 250,000 but also makes some comparisons within a wider area of South Wales with a population of around 600,000 .

\section{SCHOOL CATCHMENT ANALYSIS}

A school catchment is the area defined by the local education authority as that from which a school draws its pupils. For secondary or high schools, the catchment is usually an amalgam of primary or elementary school catchments. School catchments are known to influence residential choices. Properties for sale are advertised as belonging to a particular school catchment and parents have been known to move house to ensure that their children have the right to attend a particular school. The school catchment data were derived from the national census and comprised fifteen variables. A sixteenth variable was added from the published league tables for schools, namely the key measure of attainment at ages sixteen. A Principal Component Analysis of this data set produced a leading component with an Eigen value of 9.9 that accounted for $61.9 \%$ of the variance. This component was a clear social class dimension and the second, much less powerful component accounting for $12.8 \%$ of variance had an ethnic quality (Herbert and Thomas, 1998). This procedure was applied both to the 11 school catchments within the city of Swansea and to the fifty-five catchments that covered a wider area of South Wales. Both sets of results revealed a strong 
social class dimension and the fact that this dimension was highly correlated with the measure of educational attainment (Tables 1 and 2). As a second form of multivariate analysis, a stepwise regression procedure was applied to the same data set using the attainment measure as the dependent variable. Table 3 shows the sequence of steps and confirms the strong correlation of attainment with step 1 , a social class measure, which accounted for $70.6 \%$ of the variance.

Table 1:Principal Component 1 (Swansea)

\begin{tabular}{|l|l|l|l|}
\hline \multicolumn{3}{|l|}{ Social Class } \\
\hline+ & Low & - & High \\
\hline 0.99 & social classes 4 and 5 & 0.93 & Social classes 1 and 2 \\
\hline 0.96 & Unemployed & 0.92 & Over 6 rooms \\
\hline 0.93 & Long-term illness & 0.88 & Attainment \\
\hline 0.92 & Lone-person household & & \\
\hline 0.92 & No diplomas or degrees & & \\
\hline 0.88 & Without a car & & \\
\hline
\end{tabular}

Table 2: Principal Component 1 (South Wales)

\begin{tabular}{|l|l|l|l|}
\hline \multicolumn{3}{|l|}{ Social Class } \\
\hline+ & Low & - & High \\
\hline 0.94 & Unemployed & 0.91 & Over 6 rooms \\
\hline 0.91 & $\begin{array}{l}\text { Non-earner household with } \\
\text { dependent children }\end{array}$ & 0.89 & Social classes 1 and 2 \\
\hline 0.90 & Social classes 4 and 5 & $\mathbf{0 . 8 1}$ & Attainment \\
\hline 0.88 & No diplomas or degrees & 0.77 & Owner occupiers \\
\hline 0.87 & Without a car & & \\
\hline
\end{tabular}

Table 3: Stepwise multiple regression of V16 (pupils achieving five or more grade A-C passes, GCSE 1992-6) with census indicators of catchments

\begin{tabular}{|l|l|c|c|}
\hline $\begin{array}{l}\text { Entered } \\
\text { on step }\end{array}$ & Census indicator & Mult. $r$ & $r^{2}$ \\
\hline 1 & V1 Social classes I and II & 0.840 & 0.706 \\
\hline 2 & V5 Unemployed & 0.885 & 0.783 \\
\hline 3 & V2 Social classes IV and V & 0.898 & 0.806 \\
\hline 4 & V13 LA housing & 0.909 & 0.827 \\
\hline
\end{tabular}

This form of analysis based on census data was extended to a graphical mode by classifying the schools according to their overall attainment score and mapping these against a background of less socially advantaged residential areas. Figure 2 shows this pattern, which is again a clear expression of the link between school performance and social background of pupils. The socially disadvantaged areas are identified here by a set of three key indicators of deprivation. By 1999, the local education authority had widened its boundaries to inclu- 
de a larger set of schools (Figure 3). Some of the schools in this wider area do not have neighbourhood catchments but draw their pupils from across the local education authority area. There are, for example, Roman Catholic schools, such as Bishop Vaughan, and also schools with bilingual (Welsh and English) modes of teaching. Both of these types of school, but particularly the bilingual schools, demonstrate an effect of parental choice. It has tended to be middle-income parents who want their children to have a bilingual education and schools like Gwyr and Ystalyfera become, de facto, schools dominated by children from a better social class background. This trend has modified in recent years, especially at an elementary school level, but the generalisation remains valid. Along with this social background effect comes high attainment levels.

Figure 2: Multiple deprivation indicators and school attainment Swansea 1994

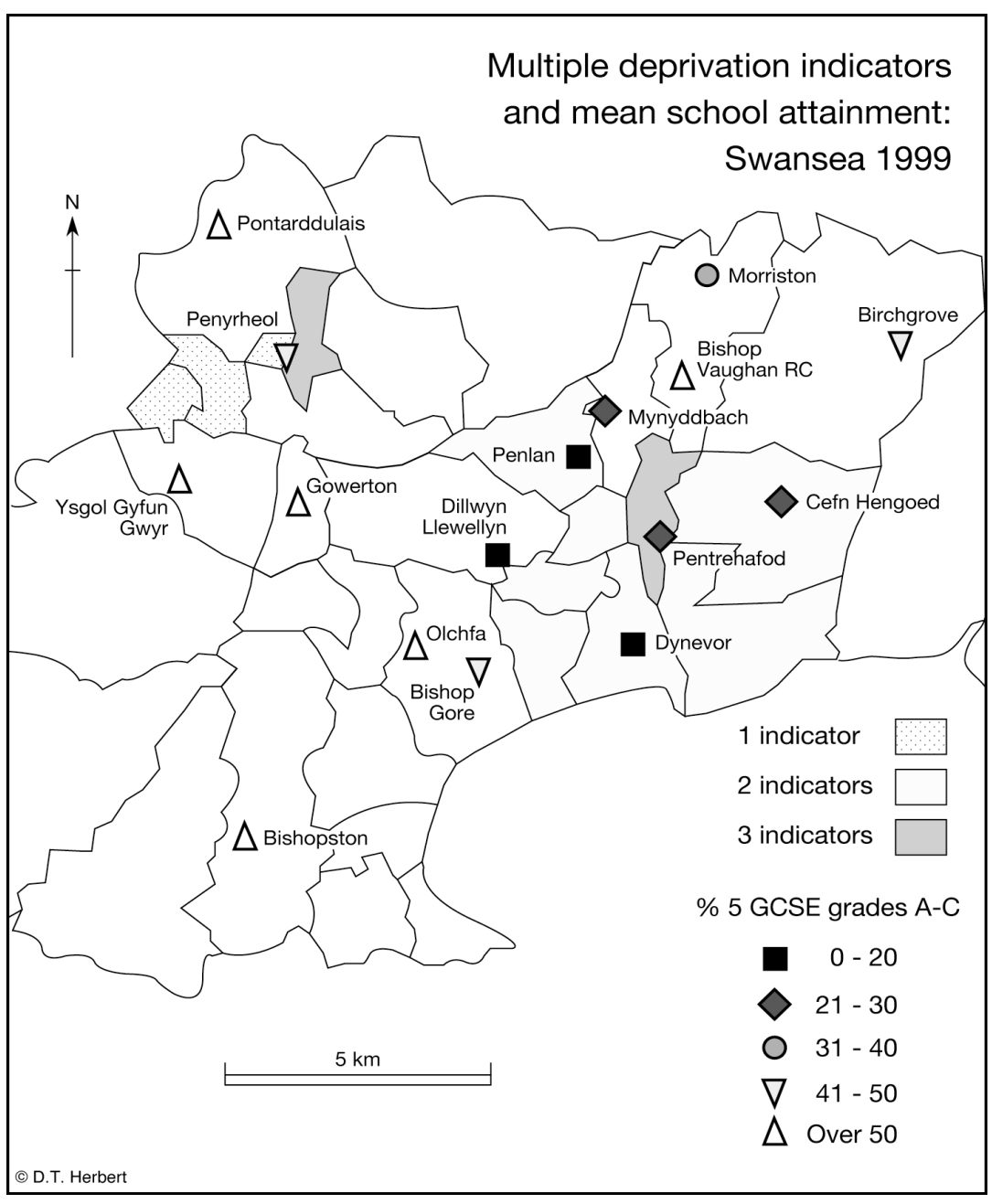




\section{SCHOOL LEVEL DATA}

Data from the local education authority enabled a second scale of analysis to be followed, that of the individual school. For each school in a wider area that included districts adjacent to the city of Swansea, information was gathered on the key indicators of free school meals (FSM) and statemented (SEN) children. If their scores on FSM and SEN scores are used to rank the schools, there is a very clear correlation with the overall attainment score for that school (Table 4). Within this ranking that conforms closely to all the information so far presented on the effect of social background, Ystalyfera and Gwyr fall into the top five schools in terms of both attainment and social class. This is not in the example of these two schools a neighbourhood effect but a demonstration of the effectiveness of parental choice.

Figure 3: Multiple deprivation indicators and school attainment Swansea 1999

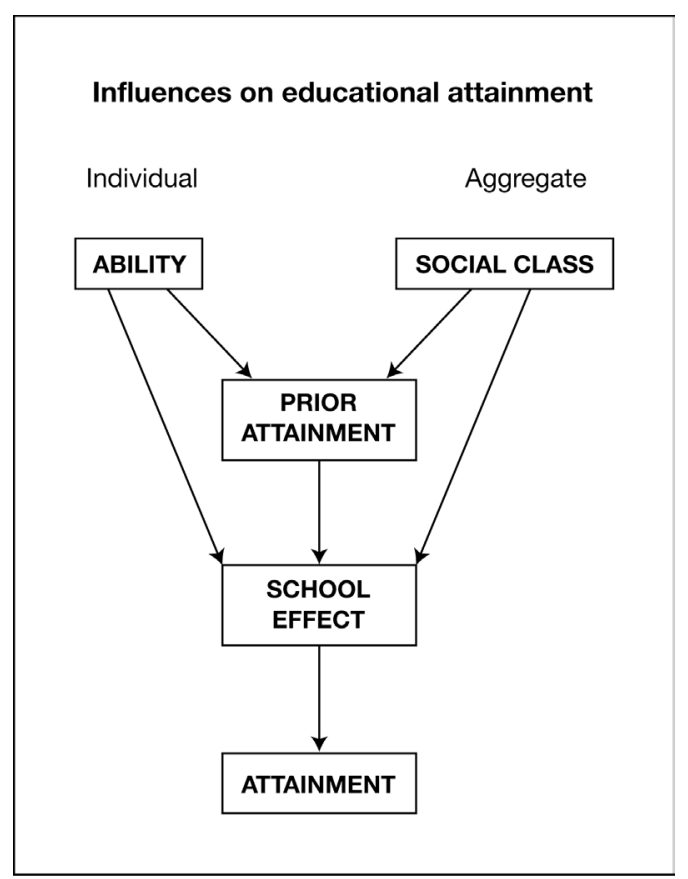

Table 4: Scores by individual schools

\begin{tabular}{|l|l|c|l|}
\hline \multicolumn{2}{|l|}{ Social disadvantage index (SEN + FSM) } & \multicolumn{2}{|c|}{ Attainment (5 A-C) } \\
\hline Rank & $1=$ most disadvantage & Rank & $1=$ lowest attainment \\
\hline 1 & Dillwyn Llewellyn & 1 & Dynevor \\
\hline 2 & Dynevor & 2 & Sandfields \\
\hline 3 & Cymer Afan & 3 & Cefn Hengoed \\
\hline 3 & Sandfields & 4 & Cymer Afan \\
\hline 3 & Penlan & 5 & Cwrt Sart \\
\hline 6 & Mynyddbach & 6 & Dillwyn Llewellyn \\
\hline
\end{tabular}




\begin{tabular}{|l|l|c|l|}
\hline 6 & Cefn Hengoed & 7 & Penlan \\
\hline 8 & Cwrt Sart & 7 & Pentrehafod \\
\hline 8 & Llangatwg & 9 & Mynyddbach \\
\hline 10 & Cefn Saeson & 10 & St Joseph's \\
\hline 10 & Birchgrove & 10 & Cwmtawe \\
\hline 12 & Pontarddulais & 12 & Llangatwg \\
\hline 13 & Pentrehafod & 13 & Cefn Saeson \\
\hline 13 & Cwmtawe & 14 & Morriston \\
\hline 15 & Penyrheol & 15 & Dyffryn \\
\hline 18 & St Joseph's & 17 & Bishop Gore \\
\hline 19 & Gowerton & 19 & Penyrheol \\
\hline 19 & Dwr y Felin & 19 & Dwr y Felin \\
\hline 21 & Morriston & 21 & Gowerton \\
\hline 22 & Bishop Gore & 22 & Ysgol Gyfun Ystalafera \\
\hline 23 & Ysgol Gyfun Gwyr & 23 & Pontarddulais \\
\hline 24 & Ysgol Gyfun Ystalafera & 24 & Olchfa \\
\hline 25 & Olchfa & 25 & Ysgol Gyfun Gwyr \\
\hline 26 & Bishopston & 26 & Bishopston \\
\hline
\end{tabular}

Spearman's $R=0.84$

(significant at 0.1\%)

\section{PARENTAL CHOICE}

It is with this theme of parental choice and its effect that I wish to conclude this paper. During the 1990s in the United Kingdom, a series of educational policies were instituted that have served to strengthen the social class effect and to widen the disparities between individual schools. Key steps in this broad pattern of change in educational policy were the establishment of local management of schools (LMS) that loosened the control of the local education authorities and granted greater autonomy to individual schools and the establishment of the principle of parental choice. This latter change allowed parents to send their children to schools outside their normal catchment provided that certain conditions were met. The impacts of these policy changes were various:

- Those parents most likely to exercise choice were those who were most aware of the advantages of particular schools, had a strong commitment to the education of their children through to a tertiary level, and were knowledgeable about the school league tables.

- Head teachers had an incentive to recruit more pupils because their funding was driven by numbers of pupils on the school roll.

- There was therefore an emerging market place in education with schools seeking to attract pupils and parents seeking places in what they perceived to be the better schools.

- The head teachers exercised some control because they could determine whether or not their school could accept more or less pupils from outside the catchment. Their judgement was influenced by the need to increase income but also possibly by the thought of enrolling 'good' pupils who would achieve well in the national examinations. This latter effect would be to improve the school league table position. 
The information base for this part of the study is qualitative (Herbert, 2000). A number of interviews were held with 38 head teachers or their deputies in the study area and included elementary as well as secondary schools. The findings can be stated and supported by a quotation that illustrates the experiences of different kinds of schools.

Statement 1. The extent to which the opportunity for parental choice was used and the movement of pupils to schools outside their normal catchment was increasing during the 1990s:

- "Preferred placement started as a trickle but now upwards of $15 \%$ of parents are making requests to other schools, mainly because of the published league table results". (Elementary school Head teacher).

- "Now we are getting literature and invitations to open days from schools that are further away; we are getting literature from all of the comprehensive (secondary) schools. It is a much more positive attempt to attract pupils from other catchments". (Elementary school Head teacher).

Statement 2: The process is producing clear losers in the educational system, especially among the secondary schools. Those schools that perform less well in the published league tables and are perceived to be less advantageous schools are losing many of their pupils.

- "We are losing pupils to Bishop Gore. I think that this is a trend associated with the owner-occupiers who live in Mount Pleasant. It is about social class. The numbers we lose in any one-year can be more than 30, a whole school class really. You have Bishop Gore on the one hand with its green, tree-lined avenue up into the school and its own swimming pool - there is no contest". (Secondary school Deputy Head teacher).

Statement 3: There are clear winners as schools that already have a good record of performance in the league tables and are perceived to be good schools, attract pupils from outside their catchments.

- "The staying-on rate for our sixth form is $70 \%$. We also get over 80 transfers each year from other schools and from colleges into our sixth form. Our academic achievement is a big factor. We had a pass rate of $96 \%$ last year and that is phenomenal in terms of educational attainment". (Secondary Head teacher).

Statement 4: The parents who want to achieve placements for their children are strongly influenced by the perceived better performances of some schools over others in terms of the attainment measure. They are also affected by more general assessments of school environments and effectiveness. There was evidence that parents were going to the length of organising buses and other forms of transport to take children to non-neighbourhood schools and that some schools were offering to arrange transport. These parents generally were strongly motivated for their children to succeed at school and were committed to strong home support. Many school head teachers were particularly interested in attracting this kind of pupil from this sort of home background.

- "The publicity and marketing of Bishop Gore was drawing pupils away from us but then they began to ask for details of the academic records of children. We were unwilling to provide that kind of information and as a result Bishop Gore was getting the sorts of children they did not want. They are now less enthusiastic about poaching pupils". (Secondary school Head teacher) 
The overall effect of the operation of parental choice has been to compound the social background effects already identified as an integral part of the educational landscape. As educational policy has introduced market principles into this landscape, so both schools and parents have begun to behave in entrepreneurial ways. The behaviour has been selective in the sense that parents seeking to exercise choice have tended to be those from better social backgrounds and schools have started their marketing activities from different bases. It is an uneven playing field. These observations of the ways in which parental choice has operated in part of South Wales are supported by a larger study of schools in Scotland (Willms, 1997). This study concluded that:

- Parents in larger cities were the most likely to exercise choice because of the wider range of accessible options. Parental choice was much less prevalent in rural areas.

- Parents of higher social class and parents with higher levels of education were more likely to exercise choice.

- Parents tended to express choice to avoid the school in their catchment area, rather than find the best school for their child. Reasons for rejection of their local school was often linked to social factors and the disciplinary regime.

- Parents tend to choose schools with higher socio-economic status and better examination results.

- Segregation between schools along social class lines increased substantially during the period when choice reform was proceeding.

This study, which is in effect a report on a number of research projects completed in Scotland, confirms the findings projected for South Wales. The Scottish study had the advantage of over 600 interviews with parents in addition to scrutiny of school records and provides information that is complementary to the Swansea study.

\section{CONCLUSIONS}

There are several key factors that affect the educational attainment of pupils at the critical points of their schooling and the contention here is that social background of the child is clearly one of these. That some children are able to overcome the burden of a disadvantaged social background and succeed at school is acknowledged but many do not. The other key factors include the ability of individual children, we are not all equally blessed with intelligence, aptitudes and energy, and a much researched factor is the so-called 'school effect'. The United Kingdom government has an elaborate system of school inspection that classifies schools into the successful and less so, and aims in a constructive way to improve the quality of the school environment. The classification of 'failing school' has been contentious and involves radical reform of a school regime. The relevant argument here is that good schools produce better levels of attainment and this has to be a truism. There is a debate about whether there are good schools or good teachers and the notion that the school itself is an aggregate that contains different levels of performance. A further dimension to the school effect argument that bears relevance to this study is that which revolves around 
the 'value-added' concept. A school in an advantaged catchment produces good examination results but are these better than the more modest achievements of a school in a disadvantaged catchment. Value added seeks to measure the improvement achieved from point of entry to point of exit rather than an absolute end of schooling measure.

The geography of education reflects these social processes. The highest achieving schools are those that draw pupils from higher social class residential areas. The children arrive with some advantage or head start that they carry through their educational career. The process of parental choice has tended to confirm these patterns and in some ways to emphasise them. The volume of movement is not high but it does work in selective ways. The already advantaged schools are those that attract more pupils and the disadvantaged schools are those that lose and end up with reduced rolls. Disparities widen and the concept of a 'sink school' becomes a reality. This has been the Swansea experience since this study was completed and the most disadvantaged school has now been closed because its falling rolls have made it untenable. A social process, initiated by a government policy has had the effect of sharpening the contours of social geography on what was already the uneven playing field of the city.

\section{References}

Davies, W.K.D., Herbert, D.T., 1993: Communities within Cities: An Urban Social Geography. London, Belhaven.

Douglas, J.W.B., Ross, J.M. and Simpson, H.R., 1968: All Our Future. London, Peter Davies.

Herbert, D.T. and Thomas, C.J., 1998: School performance, league tables and social geography. Applied Geography, 18, 199-223.

Herbert, D.T., 2000: School choice in the local environment: head teachers as gatekeepers on an uneven playing field. School Leadership and Management, 20, 79-97.

Reynolds, D., Creemers, B.P.M. and Peters, T., 1989: School Effectiveness and Improvement. Rion, Cardiff.

Reynolds, D. and Cuttance, P., 1992: School Effectiveness: Research, Policy and Practice. London, Cassell.

Herbert, D.T., 1999: Segregation and discrimination. Pacione, M. (ed.) Applied Geography: Principles and Practice, London, Routledge, 414-424.

Pacione, M., 2001: Urban Geography: A Global Perspective. London, Routledge.

Schnell, I. and Ostendorf, W. (eds.): Studies in Segregation and Desegregation. Aldershot, Ashgate.

Willms, J.D., 1997: Parental choice and education policy. CES Briefing, Edinburgh, Centre for Educational Sociology. 